\title{
APLIKASI PEMETAAN LAYANAN KESEHATAN BAGI PENYANDANG DISABILITAS DI KOTA BANJARMASIN MENGGUNAKAN GIS BERBASIS WEB
}

\author{
Johan Wahyudi \\ Program Studi Teknik Informatika, STMIK Indonesia Banjarmasin \\ Jalan Pangeran Hidayatullah Banua Anyar, Banjarmasin, Kalimantan Selatan \\ Email : johan77@stmik.id
}

\begin{abstract}
Abstrak-Ketersediaan ruang publik dan tempat layanan kesehatan yang ramah bagi penyandang disabilitas adalah mampu menyediakan fasilitas dan aksesibilitas bagi penyandang disabilitas. Pelayanan kesehatan juga merupakan pelayan publik yang menjadi hak warga negara dimana pelayanan tersebut bisa menyentuh semua kalangan termasuk saudara kita yang menyandang difabel namun pelayanan kesehatan di Indonesia saat ini belum memuaskan. Kota Banjarmasin mengemban amanah untuk memberikan kesempatan kesehatan yang sama bagi masyrakatnya. Hal tersebut sebagai salah satu upaya untuk pemenuhan atas kebutuhan fasilitas dan aksesibilitas untuk penyandang disabilitas di lyanan kesehatan yang ada di Kota Banjarmasin, terkait dengan pemenuhan kebutuhan sarana, prasarana, dan aksesibilitas.

Permasalahan yang terjadi dilapangan saat ini adalah penyandang disabilitas belum mendapatkan informasi tentang tempat kesehatan yang ada di Kota Banjarmasin dengan berbagai informasi yang diberikan seperti lokasi keberadaan, layanan khusus penyandang disabilitas, daftar dokter, dan fasilitas yang di sediakan. Geographic Information System (GIS) adalah sistem informasi khusus yang mengelola data dan memiliki informasil spasial (bereferensi keruangan). Dengan menggunakan GIS maka diharapkan akan lebih mudah bagi para penyandang disabilitas untuk mendapatkan informasi dan mengetahui pemetaan tempat layanan kesehatan yang ada di Kota Banjarmasin. Karena dengan adanya GIS maka akan digambarkan letak lokasi tempat kesehatan pada kondisi sesungguhnya.
\end{abstract}

Kata Kunci : Disabilitas, GIS, Fasilitas Kesehatan.

\section{PENDAhuluan}

$\mathrm{D}$ alam memberikan informasi mengenai lokasi fasilitas ramah disabilitas, teknologi informasi memiliki peran penting dalam memudahkan dan memberikan informasi dengan cepat mengenai persebaran lokasi fasilitas ramah disabilitas. Teknologi yang dapat digunakan untuk menyusun lokasi fasilitas ramah difabel salah satunya dengan memanfaatkan Sistem Informasi Geografis (SIG). Akses informasi mengenai lokasi tersebut dapat di integrasikan dalam satu sistem platform WebGIS "Accessibility for Disability" dengan menyediakan informasi lokasi yang aksesible bagi disabilitas. Platform ini juga berfungsi sebagai tempat kampanye untuk mendorong peningkatan kesadaran mengenai disabilitas.

Ketersediaan ruang publik dan tempat layanan kesehatan yang ramah bagi penyandang disabilitas adalah mampu menyediakan fasilitas dan aksesibilitas bagi penyandang disabilitas. Pelayanan kesehatan juga merupakan pelayan publik yang menjadi hak warga negara dimana pelayanan tersebut bisa menyentuh semua kalangan termasuk saudara kita yang menyandang difabel namun pelayanan kesehatan di Indonesia saat ini belum memuaskan. Kota Banjarmasin mengemban amanah untuk memberikan kesempatan kesehatan yang sama bagi masyrakatnya. Hal tersebut sebagai salah satu upaya untuk pemenuhan atas kebutuhan fasilitas dan aksesibilitas untuk penyandang disabilitas di lyanan kesehatan yang ada di Kota Banjarmasin, terkait dengan pemenuhan kebutuhan sarana, prasarana, dan aksesibilitas.

Kota Banjarmasin merupakan salah satu daerah Kota di Provinsi Kalimantan Selatan yang maju dan berkembang khususnya dalam bidang kesehatan. Dengan banyaknya pembangunan tempat layanan kesehatan diberbagai kawasan yang ada di Kota Banjarmasin maka menjadi banyak pilihan bagi warga masyaraka, namun tidak semua tempat layanan kesehatan memiliki fasilitas untuk para penyandang disabilitas. Dengan demikian penyandang disabilitas harus mendapatkan informasi tentang tempat kesehatan yang ada di Kota Banjarmasin dengan berbagai informasi yang diberikan seperti lokasi keberadaan, layanan khusus penyandang disabilitas, daftar dokter, dan fasilitas yang di sediakan.Geographic Information System (GIS) adalah sistem informasi khusus yang mengelola data dan memiliki informasil spasial (bereferensi keruangan). Dengan menggunakan GIS maka diharapkan akan lebih mudah bagi para penyandang disabilitas untuk mendapatkan informasi dan mengetahui pemetaan Tempat Kesehatan yang ada di Kota Banjarmasin. Karena dengan adanya GIS maka akan digambarkan letak lokasi Tempat Kesehatan pada kondisi sesungguhnya.

Aplikasi ini hanya dikhususkan untuk penyandang disabilitas, dengan input data - data fasilitas, layanan khusus, nama Dokter. dan output informasi lokasi keberadaan, fasilitas yang disediakan, layanan khusus, dan daftar Dokter dan untuk memberikan informasi layanan kesehatan yang sudah ditentukan tidak untuk memberikan informasi data privasi yang berkelanjutan. Diharapkan akan dapat membantu pengguna dengan menggunakan sistem terkomputerisasi sehingga memudahkan informasi secara efektif dan efisien. Serta mempermudah pengguna untuk mengakses informasi yang diberikan seperti lokasi keberadaan, petunjuk jalan, layanan 
khusus penyandang disabilitas, sarana tranportasi yang bisa digunakan, daftar dokter, dan fasilitas yang disediakan

\section{METODE PENELITIAN}

\section{A. Geographic Information System (GIS)}

Sistem Informasi Geografis (bahasa Inggris: Geographic Information System disingkat GIS) adalah sistem informasi khusus yang mengelola data yang memiliki informasi spasial (bereferensi keruangan). Atau dalam arti yang lebih sempit, adalah sistem komputer yang memiliki kemampuan untuk membangun, menyimpan, mengelola dan menampilkan informasi berefrensi geografis, misalnya data yang diidentifikasi menurut lokasinya, dalam sebuah database.

Para praktisi juga memasukkan orang yang membangun dan mengoperasikannya dan data sebagai bagian dari sistem ini.Teknologi Sistem Informasi Geografis dapat digunakan untuk investigasi ilmiah, pengelolaan sumber daya, perencanaan pembangunan, kartografi dan perencanaan rute.Misalnya, SIG bisa membantu perencana untuk secara cepat menghitung waktu tanggap darurat saat terjadi bencana alam, atau SIG dapat digunaan untuk mencari lahan basah (wetlands) yang membutuhkan perlindungan dari polusi.

\section{B. Layanan Kesehatan}

Merupakan pelaksanaan pemeliharaan kesehatan dalam rangka mencapai derajat kesehatan baik individu maupun masyarakat secara optimal.Dalam pelaksanaan pelayanan kesehatan ini terdapat hubungan antara pasien, tenaga kesehatan dan sarana kesehatan. Hubungan yang timbul antara pasien, tenaga kesehatan, dan sarana kesehatan diatur dalam kaidah-kaidah tentang kesehatan.

Dalam Sistem Kesehatan Nasional kita, penyelenggaraan pelayanan kesehatan dasar dapat berupa Upaya Kesehatan Perorangan (UKP) primer yaitu mendayagunakan ilmu pengetahuan dan teknologi kesehatan dasar yang ditujukan kepada perorangan.Penyelenggara UKP primer adalah pemerintah, masyarakat dan swasta yang diwujudkan melalui berbagai bentuk pelayanan profesional dan dapat dilaksanakan di rumah, tempat kerja maupun fasilitas kesehatan perorangan primer baik Puskesmas dan jaringannya serta fasilitas kesehatan lainnya milik pemerintah, masyarakat maupun swasta.

Ada dua kelompok yang berperan dalam pelayanan kesehatan medis atau pelayanan kedokteran yaitu Health
Receivers dan Health Providers.Health Receivers adalah penerima pelayanan kesehatan yaitu orang yang sakit atau mereka yang ingin memelihara/meningkatkan kesehatannya, sedangkan Health Providers adalah pemberi pelayanan kesehatan yang meliputi para tenaga kesehatan seperti dokter, perawat, apoteker, laboran, dan lain-lain. Kedua kelompok tersebut tentunya memerlukan kepastian dan perlindungan hukum didalam menjalankan fungsinya sebagai subyek hukum.

\section{Sumber dan Teknik Pengumpulan Data}

Penelitian ini dilakukan dengan survei lapangan berupa titik-titik koordinat lokasi fasilitas umum. Survei lapangan ini menggunakan GPS Mobile Topographer dengan sistem koordinat UTM dan akurasi posisi yang dihasilkan $1 \mathrm{~m}$ untuk menentukan posisi spasial dan wawancara untuk mengetahui fasilitas difabel di setiap lokasi yang menjadi objek penelitian sebagai sumber primer. Data shapefile peta administrasi Kota Banjarmasin dan studi kepustakaan berupa buku dan jurnal sebagai sumber sekunder.

Adapun proses pengumpulan data harus dengan metode yang tepat dan terarah sehingga data yang didapatkan lebih akurat.

Adapun teknik pengumpulan data yang digunakan, antara lain:

1. Library Research, dengan melakukan survei ke perpustakaan untuk mempelajari dan menganalisa setiap buku referensi dan literatur yang berhubungan dengan penelitian dan pembahasan yang dilakukan.

2. Interview, dengan melakukan pertanayaan secara langsung dengan pihak-pihak yang dianggap kompeten untuk dapat memberikan informasi yang sesuai diperlukan peneliti.

3. Internet Browsing, dengan mencari bahan-bahan, artikelartikel, atau jurnal-jurnal melalui internet yang berhubungan dengan penelitian.

4. Experiment, dengan melakukan analisa permasalahan untuk merancang sistem yang digunakan untuk membangun sistem informasi dan melakukan uji coba terhadap sistem yang telah di bangun.

\section{Rancangan Model Sistem}

Untuk memperjelas sistem tentang gambaran sistem aplikasi pada penelitian yang dilakukan makan dibuatlah UML dengan beberapa jenis, antara lain:

\section{Use case Diagram}

Gambar Use Case Diagram merupakan gambaran dari proses jalannya aplikasi tersebut.

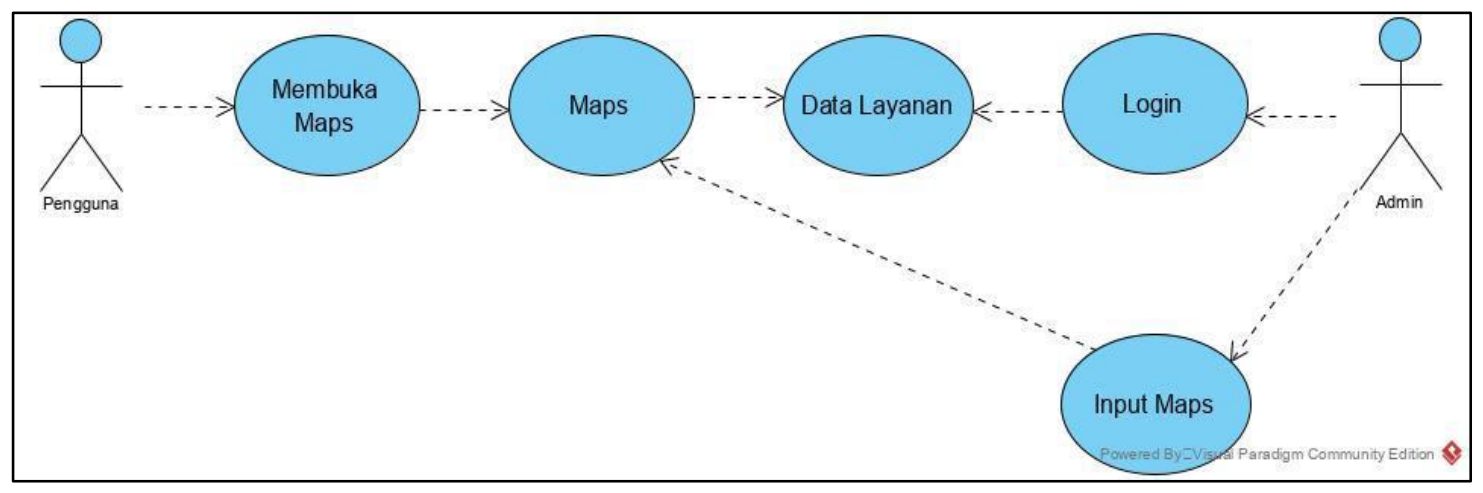

Gambar.1. Use Case Diagram 


\section{Activity Diargam}

Activity Diagram Admin Login merupakan gambaran proses jalannya halaman Admin tersebut.

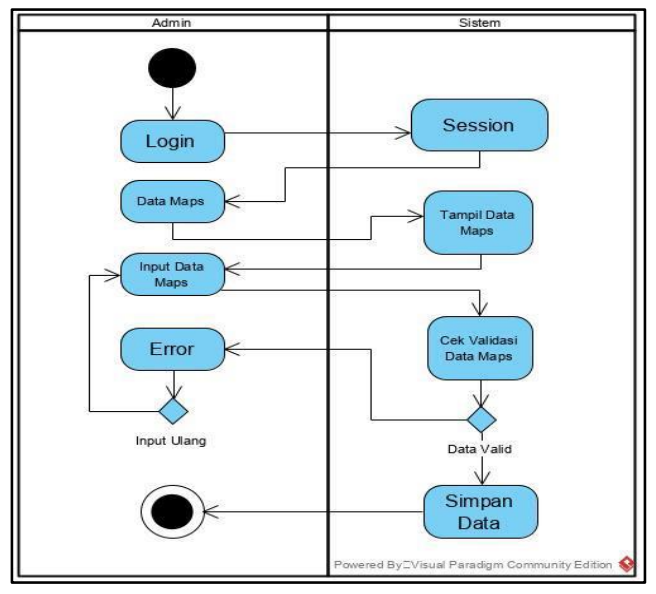

\section{Relasi Antar Tabel}

Relasi antar tabel adalah hubungan yang terjadi pada suatu tabel dengan tabel yang lainnya, yang berfungsi untuk mengatur operasi suatu database. Adapun relasi antar tabel dalam aplikasi ini adalah :

Gambar. 2. Activity Diagram dan Relasi Antar Tabel

\section{HASIL DAN PEMBAHASAN}

\section{Langkah Pembuatan Sistem}

Proses pembuatan aplikasi Geographic Information System (GIS) ini menggunakan model waterfall. Model ini melakukan pendekatan secara sistematis dan urut, mulai dari analisis kebutuhan sistem, perancangan sistem, koding, pengujian dan maintenance. Adapun langkah-langkahnya adalah sebagai berikut:

1. Analisis persyaratan dan kebutuhan

Pada tahapan ini dilakukan pengumpulan data dan informasi yang berkaitan dengan pendataan layanan kesehatan dan fasilitas yang sesuai dengan kebutuhan penyandang disibilitas. Informasi ini diperoleh melalui dengan cara secara langsung datang ke lapangan dan mewawancarai beberapa orang narasumber. Data dan informasi yang telah didapatkan selanjutnya akan dianalisis untuk mendapatkan dokumentasi kebutuhan pengguna dan digunakan pada tahapan selanjutnya.

2. Desain sistem

Tahapan selanjutnya adalah membuat rancangan untuk aplikasi Geographic Information System (GIS) untuk layanan kesehatan di Kota Banjarmasin. Rancangan yang dibuat ini meliputi rancangan model sistem, rancangan antarmuka masukan sistem hingga rancangan antarmuka keluaran sistem.
3. Implementasi

Tahapan selanjutnya adalah mulai membangun sistem. Aplikasi kelayakan kendaraan bermotor ini menggunakan Google Maps, ArcView, dan Visual Paradigm Community Edition.

4. Testing

Pada tahapan ini aplikasi yang sudah selesai diprogram akan dilakukan proses pengujian. Pengujian ini dilakukan untuk memeriksa apakah fungsi aplikasi yang dibangun sudah sesuai dengan tujuan dan keinginan.

5. Maintenance

Setelah lolos tahap pengujian, tahapan selanjutnya adalah mengimplementasikan aplikasi Geographic Information System (GIS) layanan kesehatan di Kota Banjarmasin bagi penyandang disabilitas bisa digunakan sebagaimana tujuan penelitian.

\subsection{Tampilan Aplikasi}

\section{Menu Utama}

Halaman utama pada website Tempat Informasi Layanan Kesehatan Di Banjarmasin terdapat menu Maps, menu data Layanan, data Dokter, dan data Tempat. Serta ada jumlah data Penanggung Jawab, Jumlah Dokter, Tempat Layanan, dan Informasi Layanan. 


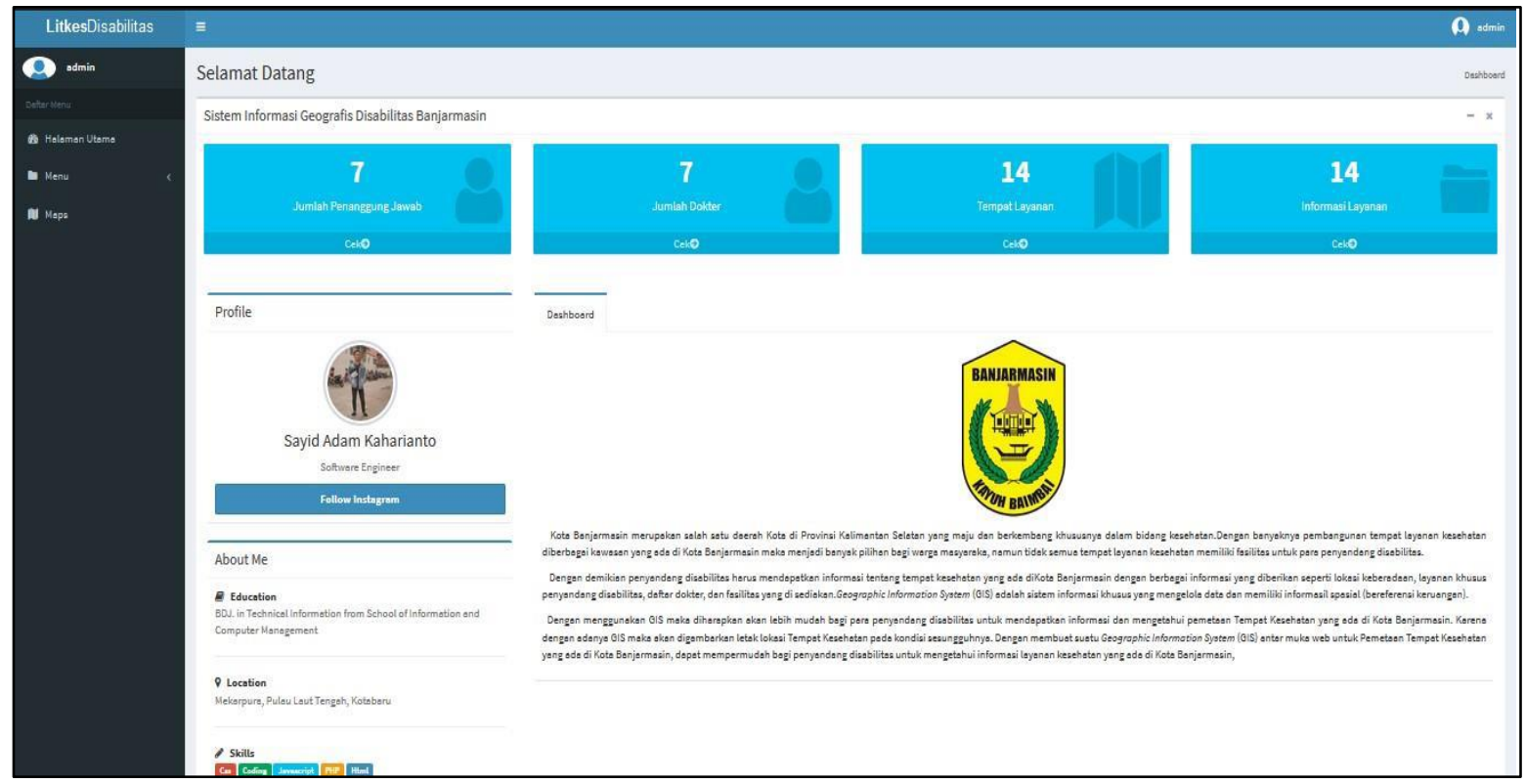

Gambar. 3. Halaman Utama Informasi Tempat Layanan Kesehatan

\section{Data Layanan}

Halaman ini terdapat data - data yang memperlihatkan informasi dari data Layanan. Terdapat beberapa tombol seperti tombol tambah layanan kesehatan, tombol di dalam kolom dokter tersedia, tombol di dalam kolom penanggung jawab, tombol edit dan hapus. Tombol tambah layanan untuk

menambahkan data layanan, tombol di dalam kolom dokter untuk membuka informasi lengkap dokter, tombol di dalam kolom penanggung jawab untuk membuka informasi lengkap penanggung jawab, tombol edit untuk merubah data, dan tombol hapus untuk menghapus data tersebut.

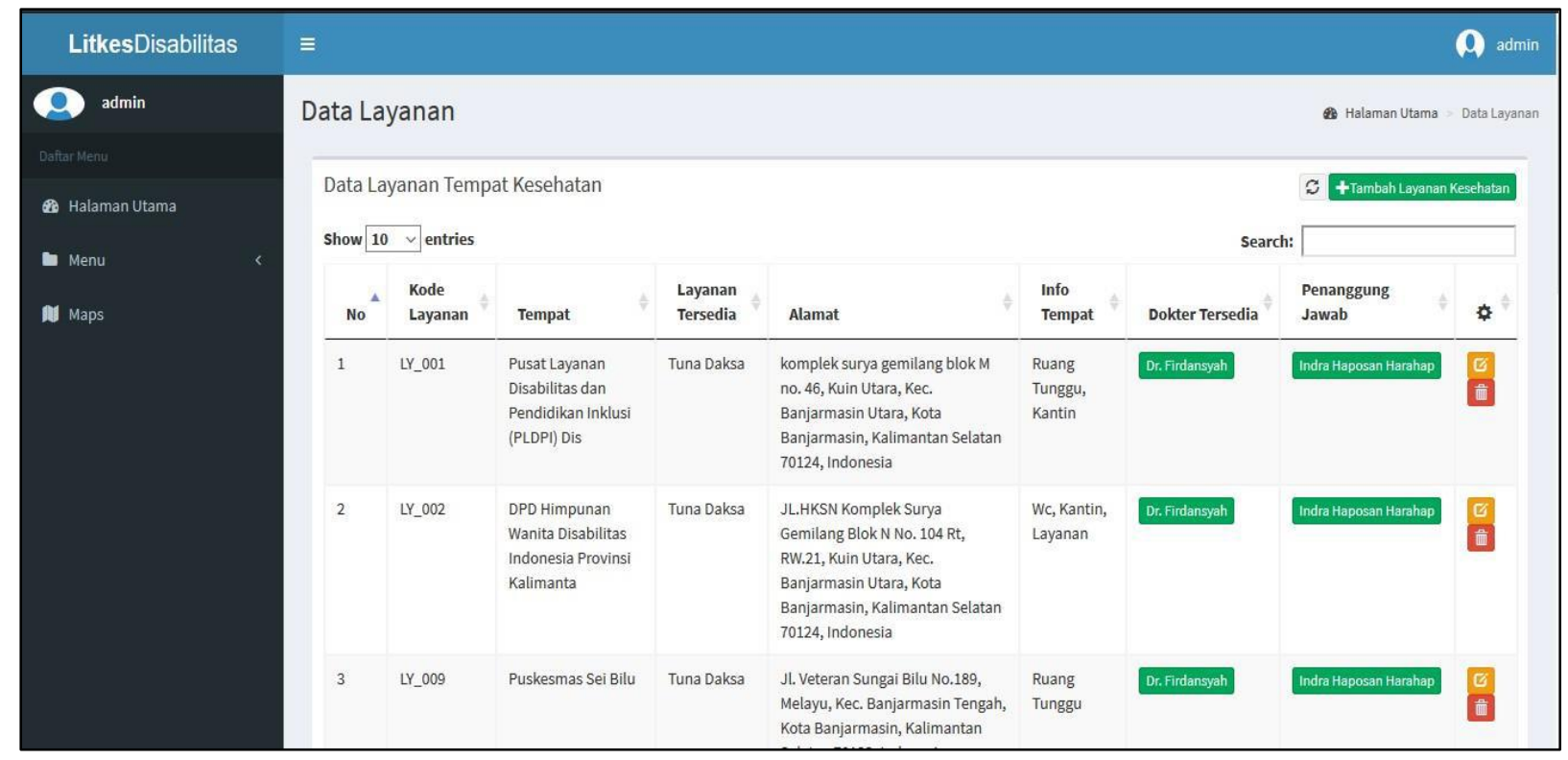

Gambar. 4. Halaman Data Layanan 


\section{Data Dokter}

Halaman dokter menampilkan data-data dokter dari kode dokter, nama dokte, alamat dokter, spesialis, dan nomor

telepon dokter. Terdapat tombol tambah dokter, edit, dan hapus.

\begin{tabular}{|c|c|c|c|c|c|c|c|}
\hline LitkesDisabilitas & \multicolumn{5}{|l|}{$\equiv$} & \multicolumn{2}{|r|}{ Q admi } \\
\hline (Q) admin & \multicolumn{5}{|c|}{ Data Dokter } & \multicolumn{2}{|c|}{ a Halaman Utama Data Dokte } \\
\hline A) Halaman Utama & \multicolumn{5}{|c|}{ Data Dokter } & \multicolumn{2}{|c|}{$\curvearrowright$ trambahi Dokter } \\
\hline & show 10 & $\checkmark$ entries & & & search: & & \\
\hline \multirow{9}{*}{ W Maps } & No 4 & Kode Dokter & Nama Dokter & Alamat Dokter & Spesialis & No Telp & $\$$ \\
\hline & 1 & DR_001 & Dr. Firdansyah & Jl. Brigjend H. Hasan Basri No.53 Sungai Miai Kec, Banjarmasin Utara & Tuna Daksa & 082174898754 & E] \\
\hline & 2 & DR_002 & Dr. Tina indah & Jl. Kuripan No.8 & Tuna Ganda & 087789233889 & (됴 \\
\hline & 3 & OR_003 & Dr. Arif Rahmansyah & Ju. P. Antasari No.139 Sungai Baru & Tuna Grahita & 088274338748 & 무표 \\
\hline & 4 & DR_004 & Dr. Bimo Prasetyo & Jl. Antasan Kecil Timur & Tuna Laras & 087287487748 & 두묘 \\
\hline & 5 & DR_005 & Dr. Heriansyah & Jl. 9 Oktober Gg. Nusa Indah No.1 Pekauman & Tuna Netra & 081283778849 & 뭄 \\
\hline & 6 & DR_006 & Dr. Raihan Farandy & Jl. Adhyaksa Jl. Kayu Tangi 1 Jalur 2 No.2 Sunga Mial & Tuna Rungu & 081288498954 & 두임 \\
\hline & 7 & DR_007 & Dr. Rizkie Fauzian & Ji. P. Antasari No.139 Sungai Baru & Tuna Wicara & 0882.74338748 & 60 \\
\hline & Showing 1 & to 7 of 7 entries & & & & Previous & Next: \\
\hline
\end{tabular}

\section{Gambar. 5. Halaman Data Dokter}

\section{Halaman Data Layanan Pada User}

Halaman ini hanya menampilkan data - data layanan seperti tempat, dokter tersedia, dan penanggung jawab. kode layanan, tempat, layanan tersedia, alamat, informasi

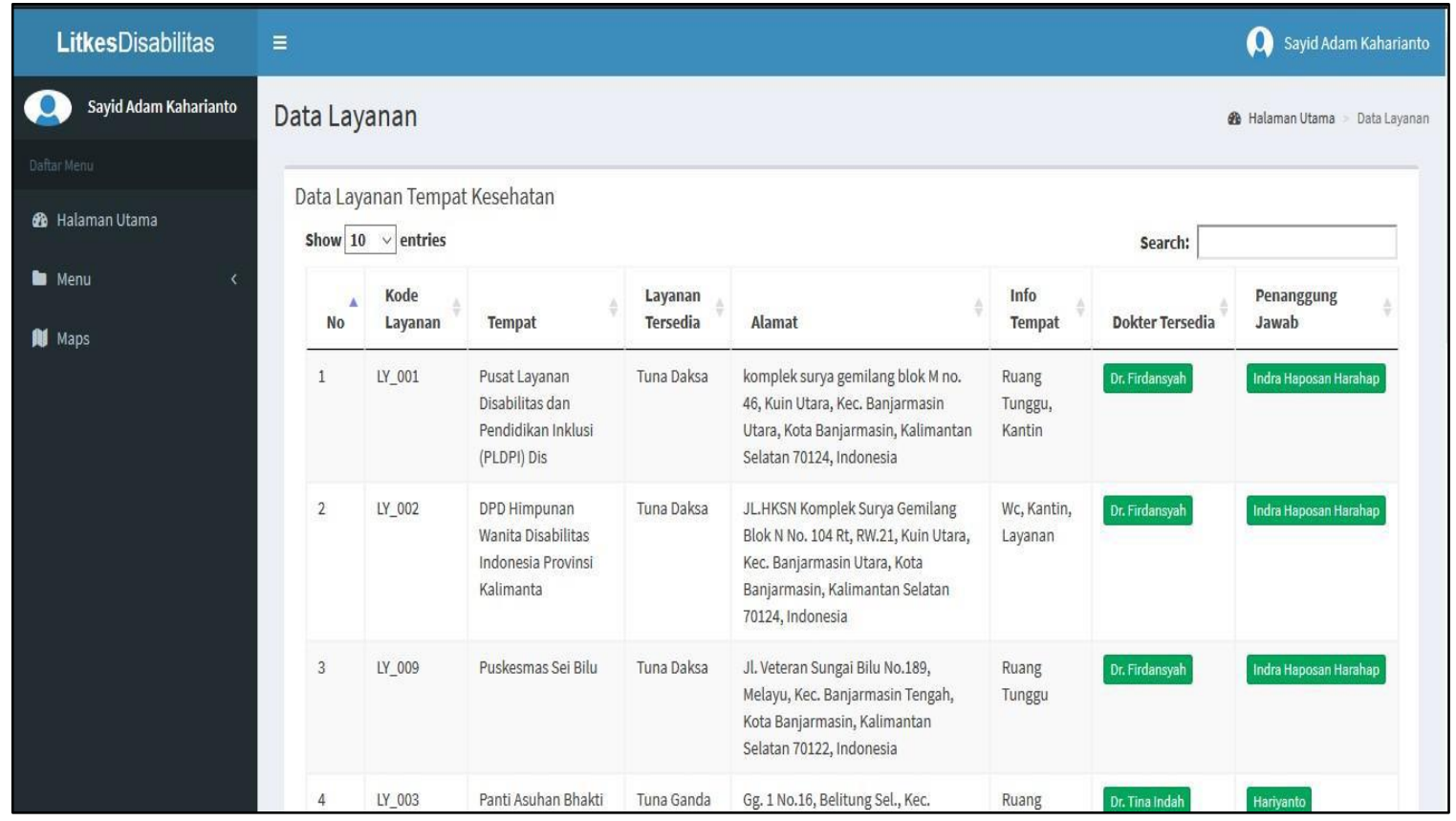

Gambar. 6. Halaman Data Layanan pada User

\section{Data Penanggung Jawab pada User}

Halaman ini menampilkan data - data pada penanggung jawab dari penyandang disabilitas 


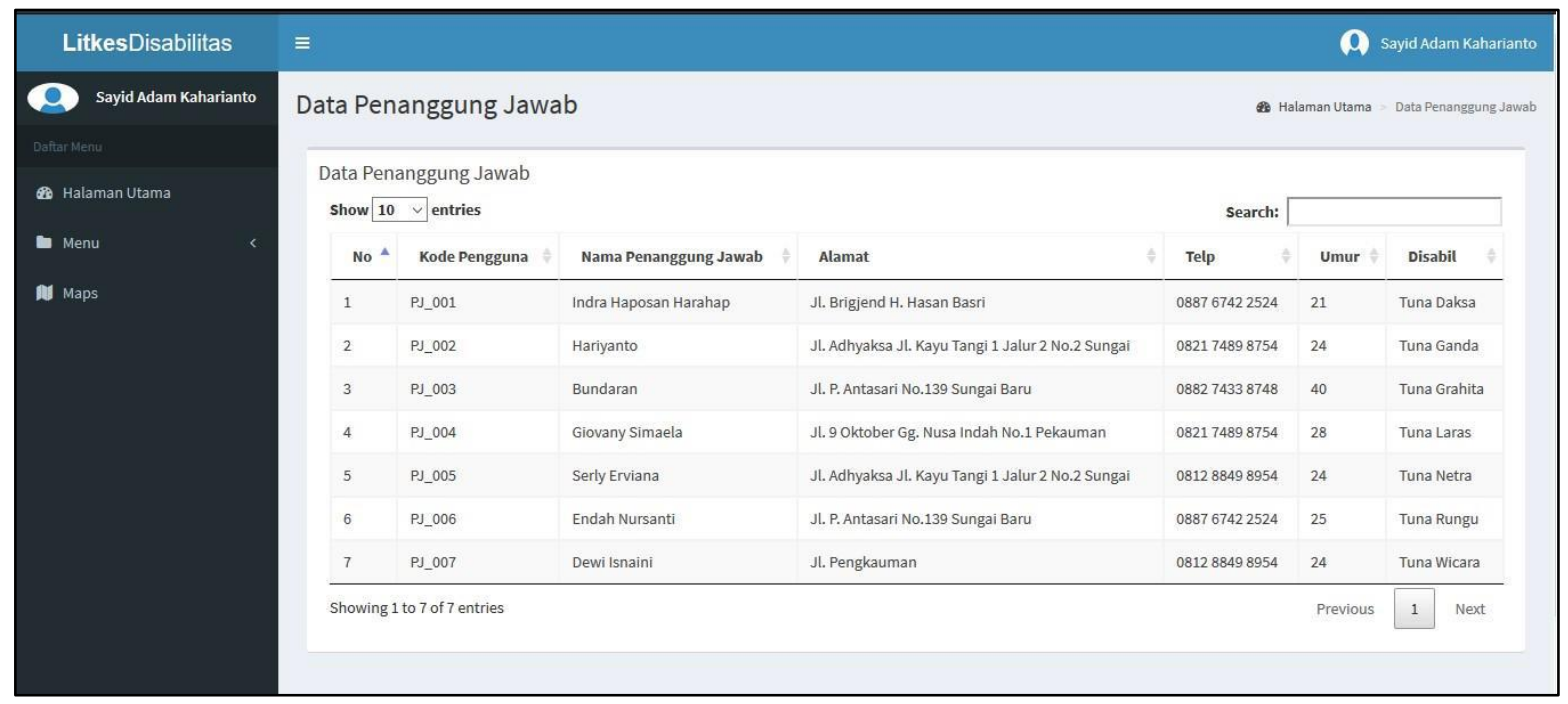

Gambar. 7. Halaman Data Penanggung Jawab pada User

\section{Data Maps}

Terdapat intro, tutorial, dan maps di halaman ini, Intro untuk memandu sebelum memulai membuka maps untuk belajar terlebih dahulu di tutorial. Halaman Maps terdapat pilihan

lokasi lengkap, Puskesmas, Rumah Sakit, dan Komunitas Disabel. Jika kita mengklik salah satunya maka akan otomatis yang ditampilkan di maps sesuai dengan yang diperintahkan.

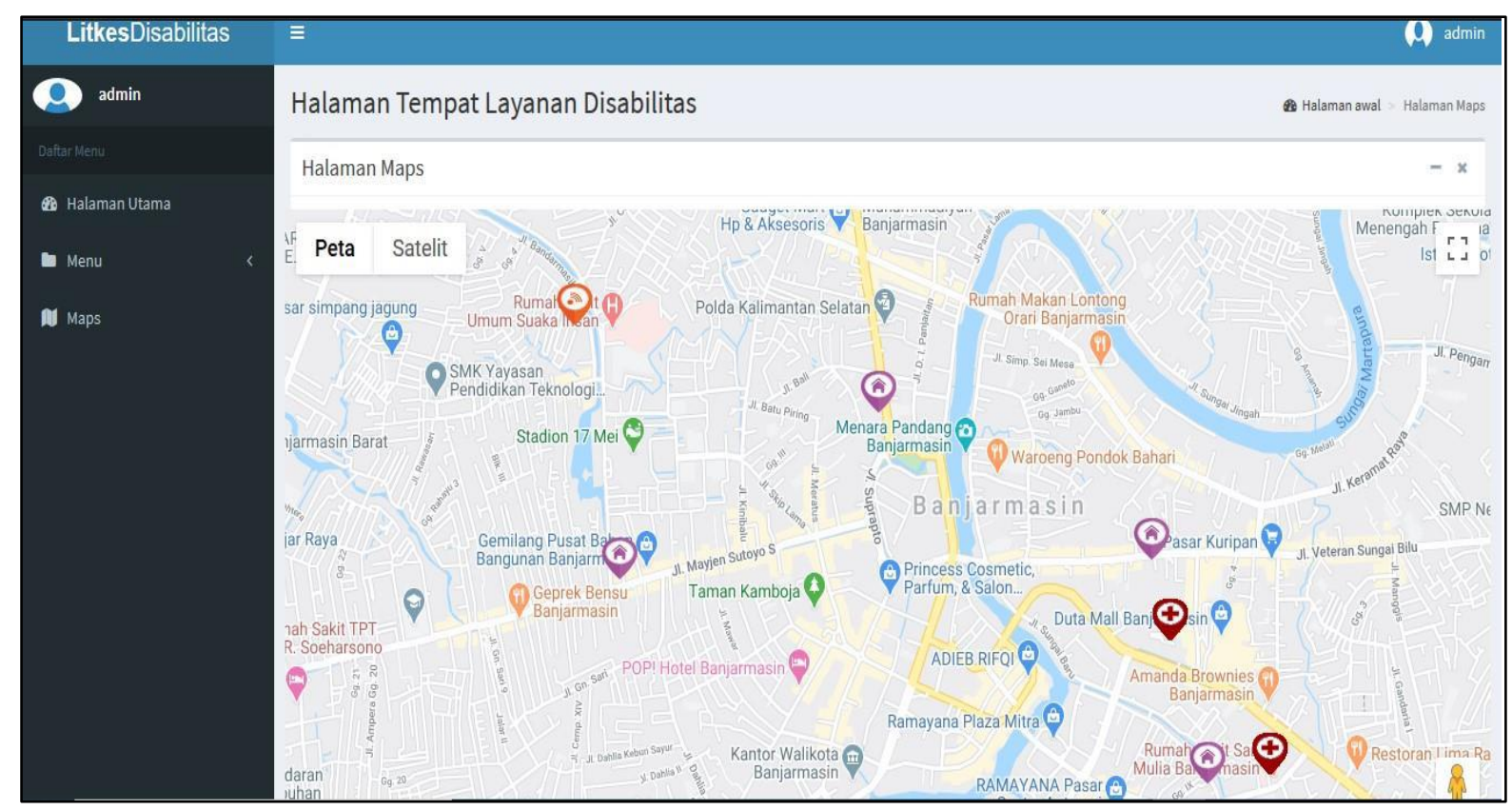

Gambar. 8. Halaman Maps

\section{Tempat Layanan}

Karena posisi sekarang login sebagai admin jadi kita bisa menambahkan titik lokasi yang ingin kita buat dengan cara mengklik kanan pada mouse kita maka otomatis akan muncul form input lalu kita tinggal mengisi form tersebut. 


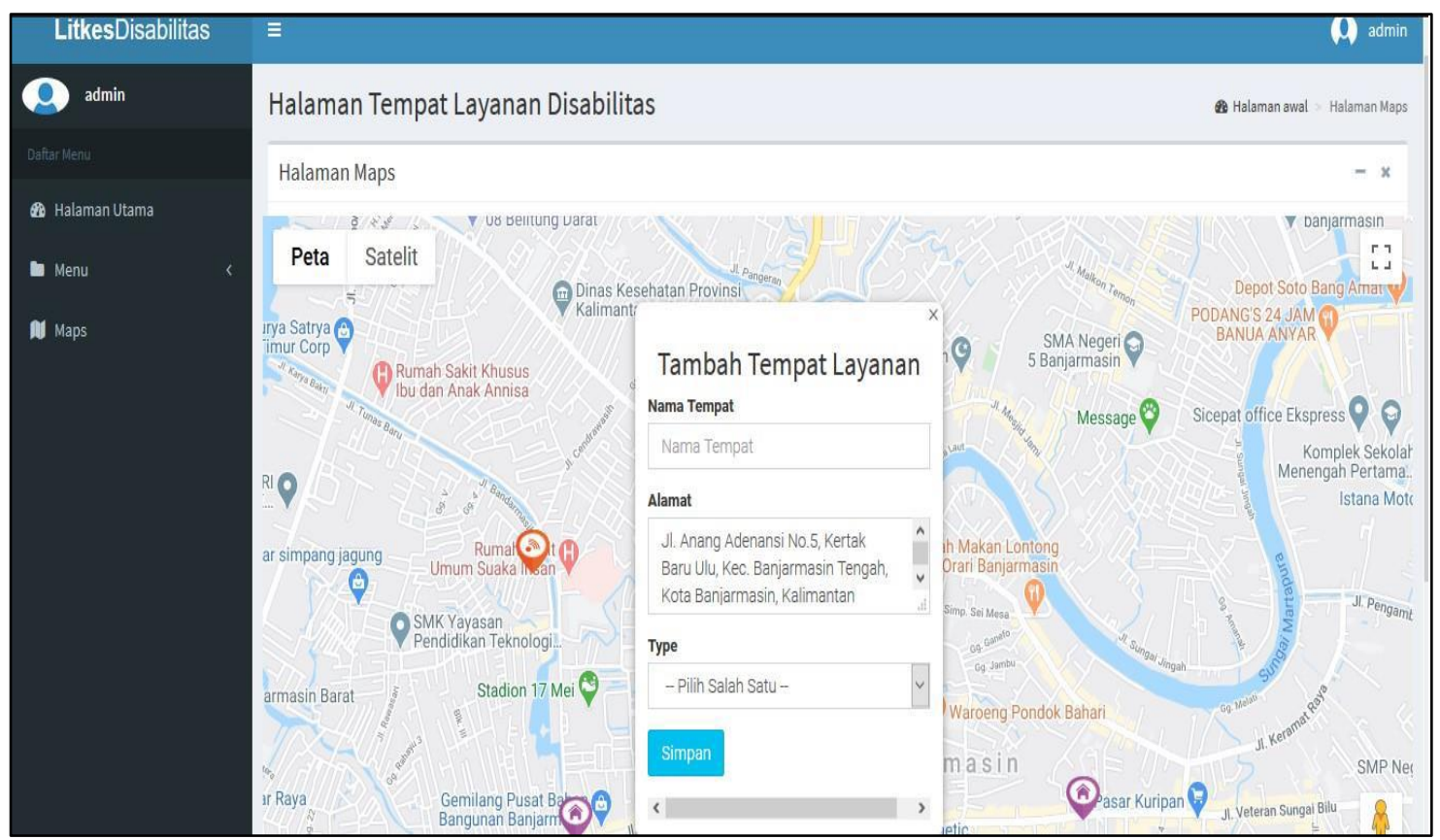

Gambar. 9. Form Tambah Tempat Layanan Pada Halaman Maps

\section{Data Informasi Tempat}

Halaman ini untuk menampilkan informasi tentang lokasi

tersebut, agar mempermudah orang melihat informasi lokasi tersebut.

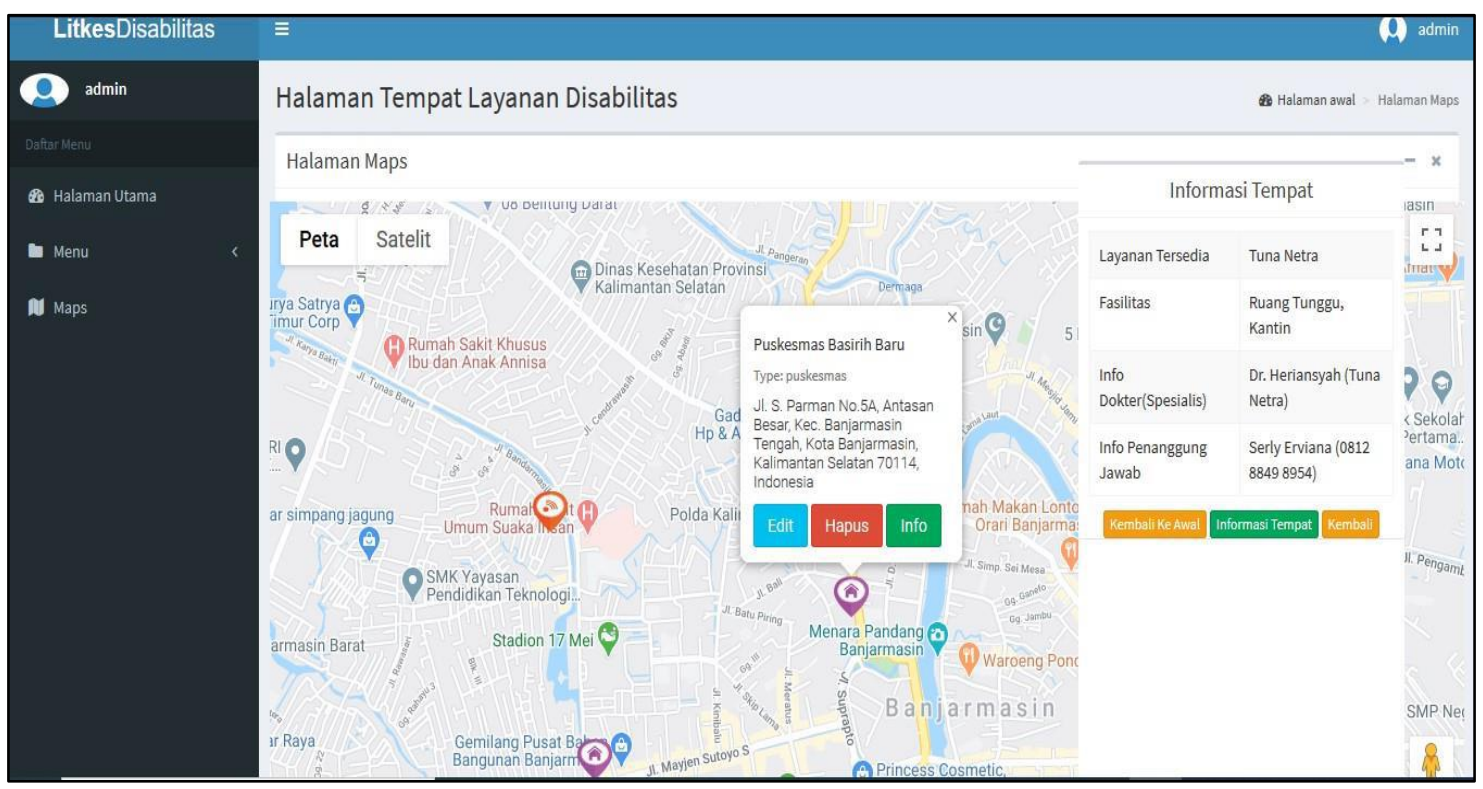

Gambar. 10. Halaman Informasi Tempat 
9. Laporan Data Layanan Informasi Kesehatan

Jika kita meng-klik laporan pada menu layanan kesehatan akan otomatis mendownload laporan dengan format pdf, seperti gambar dibawah.

\begin{tabular}{|c|c|c|c|c|}
\hline \multicolumn{5}{|c|}{$\begin{array}{l}\text { Sayid Adam Kaharianto } \\
\text { Telepon : }+6283151550686 \\
\text { JL. R.Soeprapto, No. 8, Banjarmasin, Kalimantan Selatan }\end{array}$} \\
\hline \multicolumn{5}{|c|}{ Laporan Data Tempat Dan Layanan Kesehatan Banjarmasin } \\
\hline No & Tempat & Alamat & Layanan & Fasilitas \\
\hline 1 & Pusaat Layanan Disabilitas dan Pendidikan Inklusi (PLDPI) Dis & $\begin{array}{l}\text { Komplek surya gemilang blok M no. 46, Kuin Utara, Kec. Banjarmasin Utara, Kota Banjarmasin, } \\
\text { Kalimantan Selatan 70124, Indonesia }\end{array}$ & Tuna Daksa & Ruang Tunggu, Kantin \\
\hline 2 & DPD Himpunan Wanita Disabilitas Indonesia Provinsi Kalimanta & $\begin{array}{l}\text { JL.HKSN Komplek Surya Gemilang Blok N No. } 104 \text { Rt, RW.21, Kuin Utara, Kec. Banjarmasin Utara, } \\
\text { Kota Banjarmasin, Kalimantan Selatan 70124, Indonesia }\end{array}$ & Tuna Daksa & Wc, Kantin, Layanan \\
\hline 3 & Panti Asuhan Bhakti Luhur Banjarmasin & $\begin{array}{l}\text { Gg. } 1 \text { No.16, Belitung Sel., Kec. Banjarmasin Bar, Kota Banjarmasin, Kalimantan Selatan 70128, } \\
\text { Indonesia }\end{array}$ & Tuna Ganda & Ruang Tunggu, Kantin \\
\hline 4 & Puskesmas Gadang Hanyar & $\begin{array}{l}\text { J1. Pekapuran B Laut No.14, Pekapuran Laut, Kec. Banjarmasin Tengah, Kota Banjarmasin, Kalimantan } \\
\text { Selatan 70233, Indonesia }\end{array}$ & Tuna Grahita & Ruang Tunggu, Kantin \\
\hline 5 & Puskesmas Karang Mekar & $\begin{array}{l}\text { JL. Ratu Zaleha, RT. } 15 \text { No. 210, Banjarmasin, Karang Mekar, East Banjarmasin, Banjarmasin City, } \\
\text { South Kalimantan 70236, Indonesia }\end{array}$ & Tuna Laras & Wc, Kantin, Layanan \\
\hline 6 & Puskesmas Basirin Baru & $\begin{array}{l}\text { Ju. S. Parman No.5A, Antasan Besar, Kec. Banjarmasin Tengah, Kota Banjarmasin, Kalimantan Selatan } \\
\text { 70114, Indonesia }\end{array}$ & Tuna Netra & Ruang Tunggu, Kantin \\
\hline
\end{tabular}

Gambar. 11. Laporan Data Tempat Layanan Kesehatan Untuk Penyadang Disabilitas

\section{Analisa Hasil Aplikasi GIS Layanan Kesehatan Untuk}

\section{Penyadang Disabilitas}

Dari aplikasi sistem informasi geografis layanankesehatan bagi penyandang disabilitas yang telah dijelaskan diatas, didapatkan hasil pengujian aplikikasi dari penelitian ini seperti pada tabel berikut :

Tabel 1. Hasil Pengujian Aplikasi

\begin{tabular}{c|l|l|c|}
\multicolumn{1}{c}{ No } & \multicolumn{1}{c}{ Respon Aplikasi } & \multicolumn{1}{c|}{ Keterangan } \\
\hline \multirow{2}{*}{1} & $\begin{array}{l}\text { Menyimpan data dan lokasi } \\
\text { geografis yang sesuai dengan titik } \\
\text { GPS pada maps }\end{array}$ & $\begin{array}{l}\text { Dapat menyimpan dan menampilkan data lokasi } \\
\text { layanan kesehatan }\end{array}$ & Berhasil \\
\cline { 2 - 4 } 2 & $\begin{array}{l}\text { Menyimpan data fasilitas yang } \\
\text { dimiliki oleh tempat layanan } \\
\text { kesehatan }\end{array}$ & $\begin{array}{l}\text { Dapat menyimpan data, menampilkan data fasilitas } \\
\text { layanan kesehatan }\end{array}$ & Berhasil \\
\cline { 2 - 4 } 3 & $\begin{array}{l}\text { Menampilkan hanya sebagian } \\
\text { layanan kesehatan (Puskesmas, } \\
\text { Rumah Sakit, Dokter, dengan } \\
\text { informasi layanan yang dimiliki) }\end{array}$ & $\begin{array}{l}\text { Dapat menampilakan data layanan, data dokter, dan } \\
\text { data tempat, jumlah data penanggung jawab, tempat } \\
\text { layanan, dan informasi layanan }\end{array}$ & Berhasil \\
\cline { 2 - 4 } 4 & $\begin{array}{l}\text { Aplikasi mampu menambahkan, } \\
\text { mengedit dan menghapus lokasi } \\
\text { layanan kesehatan }\end{array}$ & $\begin{array}{l}\text { Dapat melakukan perubaahan data untuk menambah, } \\
\text { mengedit dan menghapus data pada aplikasi }\end{array}$ & Berhasil \\
\cline { 2 - 4 } & $\begin{array}{l}\text { Aplikasi mampu menampilkan } \\
\text { laporan lokasi layanan kesehatan } \\
\text { yang telah disimpan }\end{array}$ & $\begin{array}{l}\text { Dapat menampilkan laporan lokasi layanan kesehatan } \\
\text { yang telah disimpan dalam aplikasi }\end{array}$ & Berhasil \\
\cline { 2 - 4 }
\end{tabular}




\section{KESIMPULAN}

Dari hasil pembahasan yang telah dijelaskan pada bab sebelumnya mengenai aplikasi sistem informasi geografis layanan kesehatan bagi penyandang disabilitas di Kota Banjarmasin dapat diambil kesimpulan sebagai berikut :

1. Aplikasi dapat membantu orang atau keluarga penyandang disabilitas untuk mencari informasi, fasilitas, dan Dokter.

2. Aplikasi dapat mempermudah orang mencari tempat khusus penyandang disabilitas contohnya seperti Puskesmas, Rumah Sakit, dan Komunitas Disabilitas.

3. Aplikasi mudah digunakan di handphone atau web karena tampilan yang minimalis dan mudah untuk digunakan.

\section{V.SARAN}

Adapun saran untuk penelitian selanjutnya yaitu sebagai berikut:

1. Beberapa kemungkinana agar dapat dikembangkan lebih baik lagi dari segi tampilan maupun menu-menu dan fasilitas yang tersedia.

2. Diharapkan aplikasi ini menjadi acuan agar lebih banyak lagi aplikasi -aplikasi berkaitan tentang GIS (Geographic Information System) yang dapat memberikan kemudahan bagi penyandang disabilitas.

3. Dapat dikembangkan lagi agar penyandang disabilitas mudah menuju lokasi layanan yang memiliki fasilitas untuk mereka dengan teknologi aplikasi untuk handphone.

\section{DAFTAR PUSTAKA}

[1] Al-Bahra bin Ladjamudin. (2005). Analisis dan Desain Sistem Informasi. Graha Ilmu, Yogyakarta.

[2] Arikunto, Suharsimi, 2006. Prosedur Penelitian. Rineka Cipta, Jakarta.

[3] Budiman Arif. 2018, Pemenuhan Hak Kesehatan Bagi Disabilitas Netra Di Puskesmas Janti Kota Malang, Malang.

[4] Djam'an Satori, 2011, Metode Penelitian Kualitatif. Alfabeta, Bandung

[5] Hasibuan Melayu S.P, 2010,Manajemen Sumber Daya Manusia. PT. Bumi Aksara, Jakarta

[6] Hesterberg, T. (2011). Bootstrap. Wiley Interdisciplinary Ulasan: Statistik Komputasi

[7] J.Bunch Martin. 2012, Using Geographic Information Systems (GIS) For Spatial Planning and Environmental Management in India: Critical Considerations, India.

[8] Lukmanul. 2004, Gregios. 2000, Yuhefizar. 1998, Pengertian Website

[9] Kenneth C. Laudon, dan Jane P. Laudon. (2005). Sistem Informasi Manajemen. Andi, Yogyakarta.

[10] Kementrian Kesehatan Republik Indonesia, 2014. Situasi Penyandang Disabilitas, Jakarta: Buletin

[11] Jendela Data dan Informasi Kesehatan.

[12] Nugroho, Adi. 2004. Konsep Pengembangan Sistem Basis data. Bandung: Informatika Bandung.

[13] Neuman, W. L. 2003.Social Research methods, Qualitative and Quantitative Approaches.Fifth Edition. Boston: pearson Education.

[14] Uml, OMG (2004). 2.0 Spesifikasi Bangunan Atas. OMG, Needham .

[15] Tata Sutabri. (2004). Sistem Informasi Manajemen. Andi, Yogyakarta.

[16] Teguh Wahyono. (2004). Sistem Informasi. Graha Ilmu, Yogyakarta.

[17] Welling, Luke, dan Laura Thomson. Pengembangan PHP dan MySQL Web . Sams Publishing, 2003.

[18] World Health Organization, 2011. World Report on Disability, Malta: WHO Library Cataloguing-in-Publication Data. 